\title{
Marc de Launay, Une construction rationnelle du judaïsme. Sur Hermann Cohen (1842-1918)
}

Genève, Labor et Fides, 2002, 126 p.

\section{Chantal Bordes-Benayoun}

\section{OpenEdition}

\section{Journals}

Édition électronique

URL : http://journals.openedition.org/assr/11073

DOI : $10.4000 /$ assr. 11073

ISSN : $1777-5825$

Éditeur

Éditions de l'EHESS

Édition imprimée

Date de publication : 1 décembre 2007

Pagination : 157-310

ISBN : 978-2-7132-2145-3

ISSN : 0335-5985

\section{Référence électronique}

Chantal Bordes-Benayoun, « Marc de Launay, Une construction rationnelle du judaïsme. Sur Hermann Cohen (1842-1918) », Archives de sciences sociales des religions [En ligne], 140 | octobre - décembre 2007, document 140-50, mis en ligne le 02 juillet 2008, consulté le 21 septembre 2020. URL : http:// journals.openedition.org/assr/11073; DOI : https://doi.org/10.4000/assr.11073

Ce document a été généré automatiquement le 21 septembre 2020

(C) Archives de sciences sociales des religions 


\section{Marc de Launay, Une construction rationnelle du judaïsme. Sur Hermann Cohen (1842-1918)}

Genève, Labor et Fides, 2002, 126 p.

Chantal Bordes-Benayoun

1 L'œuvre d'Hermann Cohen (1842-1918), fondateur de l'École philosophique de Marbourg, et connu pour sa lecture de Kant, est aujourd'hui revisitée pour les liens qui y sont construits entre tradition juive et philosophie. L'ouvrage de Marc de Launay met cette relation en perspective sur le plan biographique et historique d'une part, en montrant l'attachement profond de Cohen à la source juive; en se penchant d'autre part, sur les notions aussi centrales en théologie que celles de "révélation » et de "pardon».

2 Hermann Cohen appartient à son époque. Il est de ces juifs allemands patriotes d'avant la Première Guerre mondiale, fidèles au judaïsme et soucieux de mettre les deux héritages en harmonie. Né dans un milieu juif observant, il fut nourri de l'étude de la Torah et du Talmud et participa au séminaire rabbinique de Breslau durant quatre ans. Son penchant pour la philosophie l'amena toutefois à choisir l'université, tournant qui, contrairement à l'interprétation hâtive qui a pu en être faite, marqua moins une rupture avec la source juive qu'une volonté de rapprocher et d'allier les deux systèmes de pensée.

3 Plaidant pour une vision universaliste du judaïsme, il y puisa matière à élaboration d'une philosophie de la religion, fondée sur la vocation unitaire du message monothéiste, une éthique universelle placée au-dessus de tout et la promesse messianique d'unification du genre humain. Cette réflexion définit le rôle d'une religion non figée, soumise à une réappropriation rationnelle: "elle doit être un moyen pour faire passer l'éthique dans la culture générale » et, pour ce faire, tenue à distance de toute mythologie ou mysticisme. La Révélation et le Pardon sont réévalués à l'aune de cette nécessité première. La Révélation prolonge la création qui consiste pour Cohen en une «création de l'homme comme être de raison». Quant au pardon, 
c'est, selon Marc de Launay, le thème le plus révélateur de l'originalité de l'œuvre de Cohen et de sa fidélité au judaïsme. Cet ancrage constitue la base même de la discussion intellectuelle qui a pu et peut encore être menée. Ainsi, les philosophes juifs contemporains sont-ils en dialogue plus ou moins implicite avec le philosophe.

4 La dernière partie du livre, issu d'un séminaire de la Faculté de théologie de Lausanne (2002), fait intervenir Jean Halpérin et Raphaël Célis dans un échange qui éclaire la portée actuelle de l'œuvre de Cohen. La réflexion de Lévinas, en fut-elle nourrie ? À défaut de références exprimées, les résonances des idées philosophiques peuvent être entendues.

5 L'actualité de l'œuvre ressort du paysage intellectuel dans lequel le livre l'installe. Dans cet ouvrage de philosophie, responsabilité individuelle, rationalité et démystification apparaissent alors comme les clés d'une lecture contemporaine et d'une définition de la religion. 